\title{
ÁGUA SALINA E ESTERCO BOVINO LÍQUIDO NA FORMAÇÃO DE MUDAS DE GOIABEIRA CULTIVAR PALUMA ${ }^{1}$
}

\author{
LOURIVAL FERREIRA CAVALCANTE ${ }^{2}$, MONTESQUIEU DA SILVA VIEIRA ${ }^{3}$, \\ AILTON FRANCISCO DOS SANTOS ${ }^{3}$, WAGNER MAXIMO DE OLIVEIRA ${ }^{3}$, \\ JOSÉ ADEILSON MEDEIROS DO NASCIMENTO ${ }^{3}$
}

RESUMO- A salinidade dos solos e das águas, em muitas regiões de áreas áridas e semi-áridas do Nordeste brasileiro constitui sério obstáculo ao sistema de produção agrícola. No período de novembro de 2007 a fevereiro de 2008, foi desenvolvido um experimento para avaliar os efeitos da salinidade da água de irrigação e do esterco líquido bovino durante o período de formação de mudas de goiabeira Paluma. Os tratamentos foram distribuídos em blocos ao acaso, em esquema fatorial $5 \times 2$, referente aos níveis de salinidade da água: 0,5; 1,0; 2,0; 3,0 e 4,0 dS m ${ }^{-1}$ no solo sem e com esterco líquido bovino, em seis repetições e seis plantas por parcela. A salinidade do solo foi marcadamente elevada com o aumento da salinidade da água de irrigação, refletindo em declínio no crescimento das plantas em altura, diâmetro caulinar, área foliar, crescimento de raízes e produção de biomassa pelas goiabeiras, mas sempre com menor intensidade nas plantas com esterco líquido bovino. As plantas sob irrigação com água salina e o insumo orgânico superaram as dos tratamentos sem o insumo em 86,9; 72,4; 11,0; 252,4; 351 e 39,7\% o crescimento em altura, diâmetro do caule, comprimento de raízes, área foliar e biomassa das raízes e parte aérea, respectivamente.

Termos para indexação: Psidium guajava L., salinidade, insumo orgânico.

\section{SALINE WATER AND LIQUID BOVINE MANURE IN SEEDLINGS FORMATION OF GUAVA CULTIVAR PALUMA}

\begin{abstract}
The salinity of the soils and of the waters, in a lot of arid and semi-arid areas of the Brazilian northeast constitutes a serious obstacle for the system of agricultural production. During the period from November 2007 to February 2008 an experiment was carried out in order to evaluate the effects of the irrigation water salinity and liquid bovine manure during the seedlings formation of guava cv. Paluma. The treatments were distributed in a randomized block design, in a factorial scheme $5 \mathrm{x} 2$, referring to levels of water salinity $\left(0.5,1.0,2.0,3.0\right.$ and $\left.4.0 \mathrm{dS} \mathrm{m}^{-1}\right)$ in soil without and with liquid bovine manure in six replications and six plants per plot. Soil salinity was markedly elevated with an increasing salinity of irrigation water reflecting on decline of plant growth in height, stem diameter, leaf area, growth of roots and biomass production by guava plants, but with less intensity in plants with liquid bovine manure. The plants under irrigation with saline water and the organic product exceeded those treatments without the product at 86.9, $72.4,11.0,252.4,351.0$ and $39.7 \%$ of growth in height, stem diameter, length of roots, leaf area and biomass of roots and shoots respectively.
\end{abstract}

Index terms: Psidium guajava L., salinity, organic product.

\section{INTRODUÇÃO}

A goiabeira (Psidium guajava L.) é uma fruteira disseminada em regiões de clima tropical e subtropical, o que caracteriza ser uma planta rústica com possibilidade de se adaptar em diferentes condições edafoclimáticas. Seu fruto possui grande aceitação nos mercados interno e externo, em função do sabor agradável, aroma forte e qualidade proteica (Cavalcante et al., 2005a; Lima et al., 2008). Assim como outras fruteiras de importância econômica, é amplamente cultivada em áreas irrigadas no semiárido, situando-se entre as fruteiras de maior valor econômico para o Nordeste brasileiro (Gurgel et al., 2007; Freitas \& Alves, 2008).

As áreas de semiárido, devido ao déficit hídrico, com a irrigação, muitas vezes apresentam acúmulo de sais no solo, que compromete a formação de mudas e a capacidade produtiva das culturas, inclusive da goiabeira (Ferreira et al., 2001; Pereira

(Trabalho 067-09). Recebido em: 12-03-2009. Aceito para publicação em: 17-10-2009.

${ }^{2}$ Prof. Dr. do DSER/CCA/UFPB, Campus II, Areia - PB. lofeca@cca.ufpb.br

${ }^{3}$ Mestrando do PPGMSA/UFPB/CCA, Campus II, Areia - PB. monti_br@yahoo.com.br; ailton.agronomo@gmail.com; wagner_maximo@hotmail.com; adeilsonagro@bol.com.br 
et al., 2006; Cavalcante et al., 2007). Quanto aos efeitos dos sais, a cultura é moderadamente sensível à salinidade do solo e da água, sofrendo declínio da sua capacidade produtiva em locais onde a condutividade elétrica da água de irrigação ultrapassa 3,0 dS m-1 (Ayers \& Westcot, 1999; Cavalcante et al., 2005b). Nesse sentido, Távora et al. (2001) concluíram que as plantas de goiabeira jovens são mais sensíveis aos sais do que nas demais fases de crescimento. Para os autores, nessa fase, a cultura não tolera salinidade do extrato de saturação do solo superior $1,2 \mathrm{dS} \mathrm{m}^{-1}$ sem perda da qualidade das mudas.

A salinidade, em muitas regiões de áreas áridas e semiáridas, constitui sério obstáculo ao sistema de produção, tanto pelas alterações dos atributos físicos e químicos do solo como pela ação dos íons específicos sobre a germinação, crescimento, produção e nutrição de plantas. Essa limitação do excesso de sais também tem sido constatada na germinação das sementes e crescimento inicial da goiabeira (Hooda \& Yamdagni 1991; Pereira et al., 2006).

O excesso de sais no solo provoca redução na absorção e transporte dos elementos minerais essenciais ao desenvolvimento das plantas cultivadas em geral, inclusive da goiabeira. A redução no crescimento é consequência de respostas fisiológicas, incluindo modificações no balanço iônico, potencial hídrico, nutrição mineral, fechamento estomático, eficiência fotossintética e alocação de carbono (Sultana et al., 2002; Taiz \& Zeiger, 2006; Silva et al., 2008b). O desequilíbrio nutricional é um dos fatores mais agravantes relativo ao estresse salino, evidenciado por reduções nos teores de $\mathrm{K}$, Ca e Mg na matéria seca das raízes, caule e folhas (Távora et al., 2001; Cavalcante et al., 2005b). No solo, o excesso de sais pode elevar os valores de $\mathrm{pH}$, condutividade elétrica do extrato de saturação e comprometer as relações $\mathrm{Na} / \mathrm{Ca}, \mathrm{Na} / \mathrm{Mg}$ e $\mathrm{Na} / \mathrm{Ca}+\mathrm{Mg}$ às plantas (Pereira et al., 2006).

Ao avaliar o crescimento inicial de portaenxertos de goiabeiras (Rica e Ogawa) irrigadas com águas salinas, Gurgel et al. (2007) constataram que o incremento da salinidade da água inibiu a altura, o diâmetro do caule e o número de folhas emitidas das plantas, de ambas as cultivares, com maior severidade na cultivar Ogawa. Observaram também que a irrigação com água de salinidade, a partir de $4,5 \mathrm{dS} \mathrm{m}^{-1}$, reduziu em 63,43 e 77,41\% a fitomassa seca de ambas as cultivares, e o efeito depressivo da salinidade foi mais intenso nas raízes da cultivar Rica e na parte aérea da cultivar Ogawa.

Por ser considerada uma das mais valiosas entre as fruteiras tropicais e subtropicais, devido aos elevados teores de ferro, cálcio, fósforo, açúcares, vitamina A e do complexo B e alta digestibilidade, além da crescente expansão da área cultivada dessa fruta nos últimos anos, impulsionada pela agricultura irrigada nas áreas semiáridas do Brasil (Gonzaga Neto et al., 1999; Cavalvante et al., 2008), o cultivo da goiabeira necessita de mais informações relacionadas a sua irrigação com água de uso restrito à agricultura pelo excesso de sais, considerando que, nas regiões semiáridas, é comum reservatórios de águas dessa natureza, sendo muitas vezes a única fonte disponível.

A formação de mudas e o cultivo da goiabeira sob irrigação, na região semiárida do Nordeste, onde as águas nem sempre são de boa qualidade, está na dependência do uso de técnicas que viabilizem o manejo do solo e da água com problemas de sais. Dentre as alternativas, o esterco bovino fermentado em água, também conhecido como biofertilizante ou esterco líquido bovino (Silva et al., 2007), tem evidenciado atenuar os efeitos depauperantes da salinidade da água de irrigação no crescimento inicial de algumas culturas. Nesse contexto, Sousa et al. (2008) constataram que plantas de maracujá-amarelo irrigadas com águas de salinidade crescente, até $4 \mathrm{dS} \mathrm{m} \mathrm{m}^{-1}$, apresentaram maiores valores em altura, diâmetro caulinar, número de folhas, crescimento de raízes e acumulação de biomassa nas raízes, caules e folhas, nos tratamentos com esterco líquido bovino.

O trabalho teve como objetivo avaliar os efeitos da salinidade da água de irrigação e do esterco líquido bovino aplicado ao solo, no comportamento vegetativo de mudas de goiabeira Paluma.

\section{MATERIAL E MÉTODOS}

O experimento foi realizado em abrigo telado, no Departamento de Solos e Engenharia rural do Centro de Ciências Agrárias, Universidade Federal da Paraíba, Câmpus II, Areia - PB, durante o período de novembro de 2007 a fevereiro de 2008. O clima da região é do tipo As' de Köeppen, tropical semiúmido, com chuvas de março a julho ou agosto, e pluviosidade média anual de $1.200 \mathrm{~mm}$, com temperatura média do ar de $24{ }^{\circ} \mathrm{C}$ e umidade relativa em torno de $75 \%$, em novembro, a $87 \%$ nos meses de junho e julho, respectivamente.

Os tratamentos foram distribuídos em blo$\cos$ ao acaso, em esquema fatorial $5 \times 2$, referente aos níveis de salinidade da água de irrigação $(0,5$; 1,0; 2,0; 3,0 e 4,0 dS m${ }^{-1}$ ) no solo sem e com esterco líquido bovino aplicado ao solo, em seis repetições e seis unidades por parcela. A preparação das águas com níveis de condutividade elétrica foi feita com água fortemente salina $\left(\mathrm{CEa}=11,81 \mathrm{dS} \mathrm{m}^{-1}\right)$ diluída 
em água não salina ( $\left.\mathrm{CEa}=0,5 \mathrm{dS} \mathrm{m}^{-1}\right)$.

Como substrato, foi utilizado material dos primeiros $20 \mathrm{~cm}$ de um Latossolo Vermelho-Amarelo distrófico não salino (Santos et al., 2006), coletado no município de Areia $-\mathrm{PB}$ (CEes= 0,22 dS m ${ }^{-1}$; PST= $4,61 \%$ e pH=6,4). Foram acondicionados três litros de terra fina seca ao ar, passados em peneira de $2 \mathrm{~mm}$ de malha, em vasos plásticos com capacidade para 3,5 L. O esterco líquido bovino, ou biofertilizante, foi preparado a partir de uma mistura de partes iguais de esterco fresco bovino e água sob fermentação anaeróbia, durante 30 dias, e aplicado dois dias antes da semeadura, em volume equivalente a $10 \%$ do volume total do substrato. Antes da aplicação, o insumo orgânico foi avaliado como se fosse água para irrigação e continha a seguinte composição: $\mathrm{Ca}^{2+}=$ $10,25 \mathrm{mmol}_{\mathrm{c}} \mathrm{L}^{-1}, \mathrm{Mg}^{2+}=8,5 \mathrm{mmol}_{\mathrm{c}} \mathrm{L}^{-1}, \mathrm{Na}^{+}$ $=4,25 \mathrm{mmol}_{\mathrm{c}} \mathrm{L}^{-1}, \mathrm{~K}^{+}=4,47 \mathrm{mmol}_{\mathrm{c}} \mathrm{L}^{-1}, \mathrm{Cl}^{-}=2,71$ $\mathrm{mmol}_{\mathrm{c}} \mathrm{L}^{-1}, \mathrm{HCO}_{3}^{-}=10,25 \mathrm{mmol}_{\mathrm{c}} \mathrm{L}^{-1}, \mathrm{CO}_{3}{ }^{2-}=$ $3,13 \mathrm{mmol}_{c} \mathrm{~L}^{-1}, \mathrm{SO}_{4}^{2-}=11,02 \mathrm{mmol}_{\mathrm{c}} \mathrm{L}^{-1}$, cond utividade elétrica a $25^{\circ} \mathrm{C}=2,72 \mathrm{dS} \mathrm{m} \mathrm{m}^{-1}$ e $\mathrm{pH}=6,92$ (Richards, 1954).

A irrigação foi feita baseado no processo de pesagem fornecendo-se diariamente o volume de cada tipo de água evapotranspirada, de modo a elevar o solo ao nível de capacidade de campo. Aos 70 dias após a semeadura, foram obtidos os valores do crescimento em altura, diâmetro do caule na altura do colo das plantas, área foliar, comprimento de raiz principal, massa da matéria seca de raiz, parte aérea e total das plantas, $\mathrm{pH}$ e condutividade elétrica do extrato de saturação do solo.

O crescimento em altura e o comprimento da raiz principal foram medidos com trena métrica, e o diâmetro, com paquímetro digital. Em seguida, foram separadas de cada planta as raízes da parte aérea e postas a secar em estufa, com circulação de ar, a $65^{\circ} \mathrm{C}$, até massa constante. As amostras de terra de cada substrato foram coletadas para a obtenção do pH e a condutividade elétrica do extrato de saturação (Richards, 1954).

Os dados foram submetidos à análise de variância, pelo teste " $F$ ”, para diagnósticos de efeitos significativos de cada fonte de variação individual e de suas respectivas interações. Quantitativamente, foram interpretados por regressão polinomial para os níveis de salinidade no solo sem e com esterco líquido bovino ou biofertilizante.

\section{RESULTADOS E DISCUSSÃO}

A interação salinidade da água x esterco líquido bovino não exerceu efeito significativo, mas o aumento da salinidade da água, independentemente da ausência ou presença do insumo orgânico no solo, inibiu linearmente o crescimento em altura e diâmetro das goiabeiras, ao nível de 1,55 cm (Figura 1A) e $0,11 \mathrm{~mm}$ (Figura 2A), respectivamente, por cada aumento unitário de condutividade elétrica da água de irrigação. Verifica-se, nos tratamentos irrigados

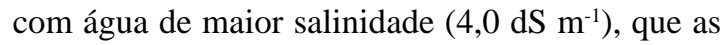
plantas apresentaram declínio de 38,4\% na altura em relação às submetidas à água de $0,5 \mathrm{dS} \mathrm{m} \mathrm{m}^{-1}$. Por outro lado, as plantas que foram irrigadas com as respectivas águas no solo com esterco líquido bovino, tiveram um crescimento de $86,91 \%$ a mais em relação às que não receberam o insumo (Figura1B). Essa superioridade evidencia a ação atenuante do insumo orgânico aos efeitos negativos dos sais sobre o crescimento em altura das plantas. Silva et al. (2008a) verificaram que a aplicação de esterco bovino (3kg em 100kg de solo) elevou significativamente a altura de goiabeiras Paluma irrigadas com água salina. Segundo os mesmos autores, a aplicação de materiais orgânicos, além de melhorar a estrutura do solo reduz a formação de crosta superficial, o que implica melhor taxa de infiltração e respiração das raízes e consequente maior crescimento das plantas em altura. Nos tratamentos com água salina sem o biofertilizante, a inibição do crescimento inicial da goiabeira devido à salinidade foi semelhante à constatada por Cavalcante et al. (2005b) e por Gurgel et al. (2007). A inibição no crescimento foi provocada pelo excesso de sais do substrato, resultando na diminuição dos efeitos osmóticos e iônicos, reduzindo a expansão e a divisão celular (Sultana et al., 2002; Munns et al., 2006).

O diâmetro do caule apresentou um declínio de 26,85 \% nas plantas irrigadas com a água mais salina $\left(4,0 \mathrm{dS} \mathrm{m}^{-1}\right)$ em relação à de menor salinidade $\left(0,5 \mathrm{dS} \mathrm{m}^{-1}\right)$ (Figura 2A). Comparativamente, a influência dos efeitos está em acordo com a apresentada por Távora et al. (2001) após avaliarem o crescimento de dois genótipos de goiabeira sob irrigação com águas salinas. De forma semelhante à constatada para altura, o diâmetro das plantas submetidas à aplicação de biofertilizante e águas salinas teve um incremento de 72,41 \% em relação às que não receberam o insumo (Figura 2B). Avaliando o desenvolvimento inicial de quatro cultivares de goiabeira (Pentecoste, Paluma, Surubim e IPA B-38), Cavalcante et al. (2007) também verificaram decréscimos no diâmetro do caule em função do incremento de sais na água de irrigação.

O comprimento das raízes foi reduzido linearmente em função do aumento da salinidade da água de irrigação, apresentando uma perda de crescimento 
de 11,32 \% nas plantas tratadas com o nível máximo de salinidade da água $\left(4,0 \mathrm{dS} \mathrm{m}^{-1}\right)$ comparado ao valor mínimo $\left(0,5 \mathrm{dS} \mathrm{m}^{-1}\right)$, o que corresponde a uma perda de 2,31 cm por cada aumento unitário de condutividade elétrica da água de irrigação correspondente (Figura $3 \mathrm{~A}$ ). O comportamento dos dados está coerente com o obtido por Cavalcante et al. (2005b) em genótipos de goiabeiras submetidas a irrigação com águas salinas. Nas plantas tratadas com águas salinas e biofertilizante, o crescimento das raízes foi superior em $11,02 \%$ comparado às plantas que não receberam o esterco bovino líquido. Comparativamente, com o incremento de 86,91\% na altura e 72,41 no diâmetro caulinar, a ação do biofertilizante nos tratamentos com águas salinas foi menos expressiva no crescimento da raiz principal das plantas. Além dos efeitos promovidos na estruturação física do solo, o esterco bovino líquido aplicado na superfície do substrato forma uma camada de impedimento às perdas elevadas de água por evaporação, o que possibilita às células vegetais permanecerem túrgidas por mais tempo em relação às plantas que não receberam o insumo.

A área foliar das plantas decresceu linearmente com a concentração de sais da água de irrigação, independentemente da presença do insumo, mas os valores foram sempre superiores nas plantas com biofertilizante (Figura 4). Verifica-se, na referida figura, que, apesar da superioridade nos tratamentos com o esterco bovino líquido, o insumo evidencia ação atenuadora da salinidade, mas não elimina o efeito degenerativo dos sais às plantas. Nesse sentido, constata-se, a partir dos valores referentes às águas de 0,5 e 4,0 dS m-1, que a redução da área foliar foi de 58 para $18 \mathrm{~cm}^{2}$ e de 176 para $126 \mathrm{~cm}^{2}$ com perdas de 68,96 e 28,41\%, respectivamente, nos tratamentos sem e com biofertilizante. Constata-se também que, apesar da superioridade dos dados nos tratamentos com o insumo, resultando numa perda marcadamente inferior, o declínio da área foliar por incremento unitário do teor salino das águas foi superior nas plantas dos tratamentos com água salina e biofertilizante, com valores de 14,6 em relação a 8,8 no solo sem insumo. Comparativamente, o comportamento da área foliar nos tratamentos sem o biofertilizante apresentou a mesma tendência observada por Távora et al. (2001) e Cavalcante et al. (2005b) em goiabeiras irrigadas com água salina e por Sousa et al. (2008) em maracujazeiro sob irrigação com água salina e biofertilizante.

O aumento do conteúdo salino da água de irrigação inibiu linearmente a produção de matéria seca das raízes (Figura 5A), parte aérea (Figura 5B) e total (Figura 5C) das plantas, mas sempre com menor intensidade nos tratamentos com insumo orgânico. A cada aumento unitário de condutividade elétrica da água, as plantas que foram tratadas com esterco líquido tiveram uma perda 0,073; 0,109 e 0,19 g planta $^{-1}$ na matéria seca das raízes, parte aérea e total, respectivamente, e nas que não receberam o insumo, de 0,$056 ; 0,066$ e $0,1 \mathrm{~g} \mathrm{planta}^{-1}$. Apesar de as perdas por incremento unitário da condutividade elétrica da água de irrigação serem maiores nas plantas com esterco líquido bovino, como registrado também para a área foliar, foram menores nas plantas com o esterco líquido bovino em relação às plantas dos tratamentos sem o insumo, uma vez que os valores absolutos de cada variável foram sempre superiores nos tratamentos com água salina e esterco líquido. Os decréscimos percentuais dos valores entre as águas de menor e maior teor salino foram maiores nos tratamentos sem o esterco líquido bovino. Os dados de matéria seca das plantas com biofertilizante sofreram reduções de 39,7; 38,3 e 41,1 \% nas raízes, parte aérea e total, e nas plantas sem o insumo os declínios foram 92,6; 81,5 e $40 \%$, respectivamente, entre as águas de maior e menor condutividade elétrica. Comparativamente, constata-se também que, nos tratamentos sem o esterco líquido, o aumento de sais na água de irrigação prejudicou mais o sistema radicular, uma vez que as perdas foram superiores em mais de $92 \%$ no solo sem o biofertilizante, comparadas com os $39,7 \%$ no solo com o insumo orgânico. Esses resultados estão compatíveis com os dados obtidos por Távora et al. (2001) ao constatarem diminuição da matéria seca total de mudas de goiabeira sob estresse salino de $\mathrm{NaCl}$ em solução nutritiva, Cavalcante et al. (2005b) em goiabeiras irrigadas com água salina e com Gurgel et al. (2007) em porta-enxerto de goiabeira tratada com águas ricas em cloreto de sódio. Nessas situações, a perda de folhas de plantas irrigadas com água salina é reflexo da senescência precoce provocada pelos efeitos tóxicos dos sais em excesso (Munns, 2002; Silva et al., 2008b), reduzindo a área foliar e o rendimento de matéria seca. Essa inconveniência ocorre também com mudas de outras fruteiras, como observado para cajueiro-anão-precoce, aceroleira e gravioleira tratadas com águas salinas (Carneiro et al., 2002; Gurgel et al., 2003).

O solo utilizado como substrato para a formação das mudas, independentemente da adição ou não de esterco líquido, teve o $\mathrm{pH}$ reduzido linearmente com o incremento da salinidade da água de irrigação, com declínio de 0,16 unidade por aumento unitário da condutividade elétrica da água de irrigação (Figura 6A). Por outro lado, constata-se que o insumo orgânico elevou significativamente o pH de 5,98 para 6,32 (Figura 6B); esses resultados divergem de Sousa et al. 
(2008) após constatarem que o esterco líquido bovino provocou redução do pH do solo sem o insumo.

A salinidade média do solo foi expressivamente elevada com o teor salino da água de irrigação, independentemente da adição ou não do esterco líquido bovino, sendo responsável pela inibição das variáveis avaliadas, no desenvolvimento inicial da goiabeira Paluma. O caráter salino do solo foi elevado em 1,87 dS m-1 por aumento unitário da condutividade elétrica da água de irrigação. Isso significa que a água contribuiu com $87 \%$ para o aumento da salinidade do solo. Os valores aumentaram de $1,44 \mathrm{dS} \mathrm{m}^{-1}$ para 2,37; 4,25; 6,12 e
7,99 dS m-1 em função da salinidade da água de $0,5 \mathrm{dS} \mathrm{m}^{-1}$ para $4,0 \mathrm{dS} \mathrm{m}^{-1}$, respectivamente. $\mathrm{O}$ aumento da condutividade elétrica do extrato de saturação do solo (CEes), de 1,44 dS m-1, para $7,99 \mathrm{dS} \mathrm{m}^{-1}$ (Figura 7) expressa que a condição iônica do solo foi elevada de não salina (CEes 2,0 dS $\mathrm{m}^{-1}$ ) para até ligeiramente salina com condutividade elétrica próxima a $8,0 \mathrm{dS} \mathrm{m}^{-1}$ (Richards, 1954) e está em acordo com os dados obtidos por Pereira et al. (2006) e Sousa et al. (2008) após avaliarem o crescimento de plântulas de goiabeira e maracujazeiro-amarelo em substratos irrigados com águas salinas.
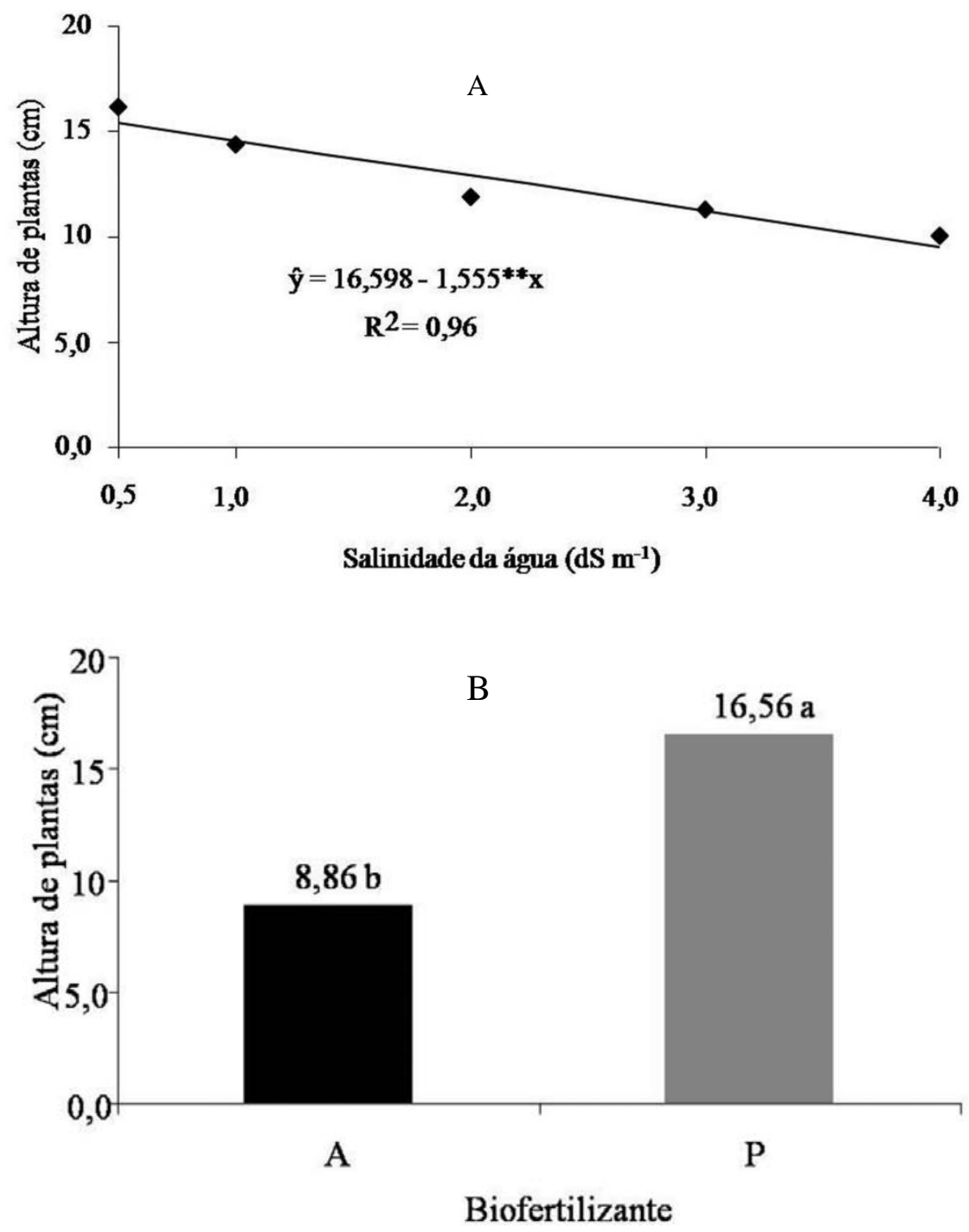

FIGURA 1 - Altura de plantas de goiabeira Paluma, aos 70 dias após a emergência, em função da salinidade da água de irrigação (A), na ausência ( $\square$ ) e presença ( $\square$ )de biofertilizante (B). 

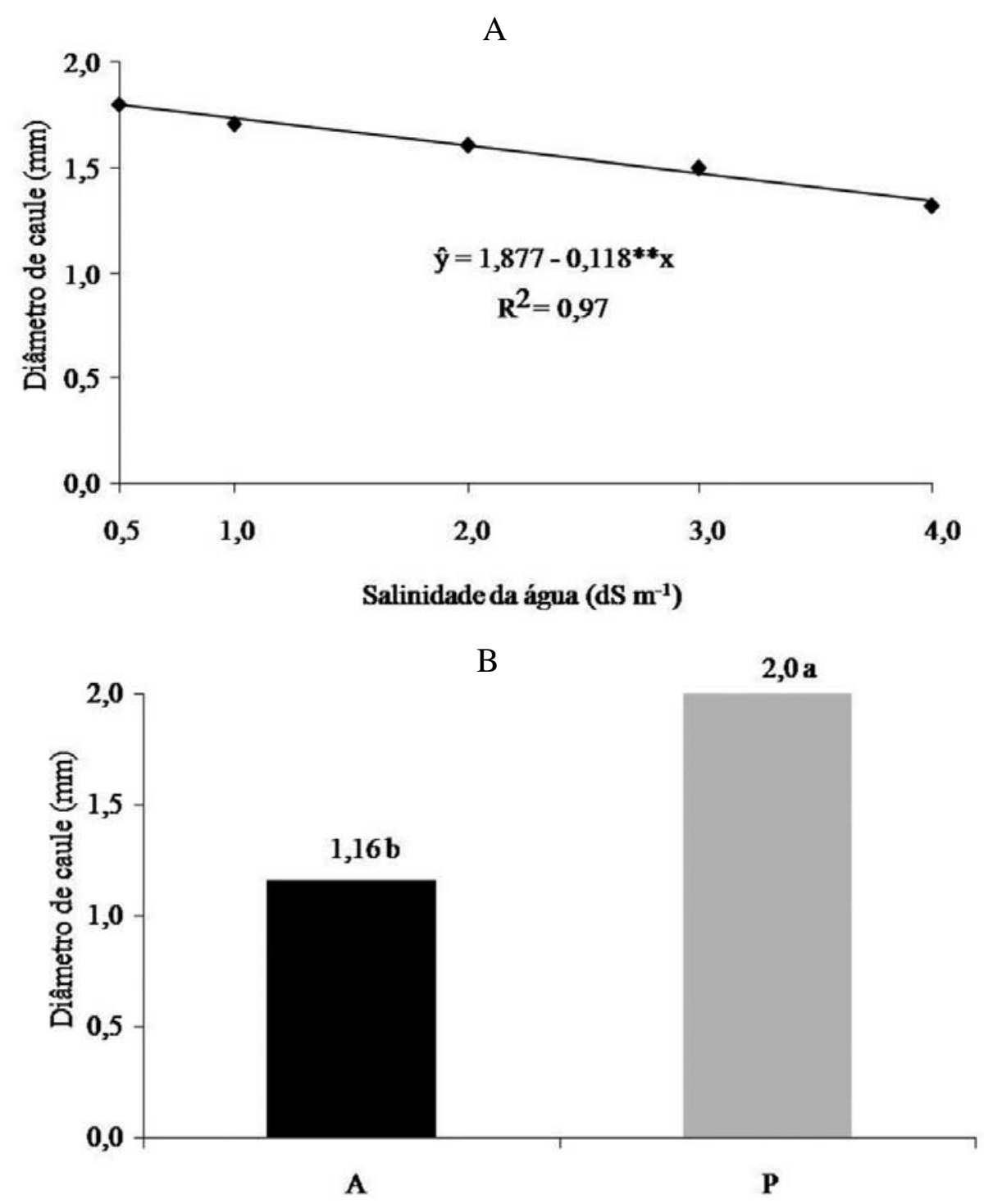

Biofertilizante

FIGURA 2 - Diâmetro do caule de plantas de goiabeira Paluma, aos 70 dias após a emergência, em função de níveis de salinidade da água de irrigação $(A)$, na ausência $(\boldsymbol{\square})$ e presença ( $\square$ ) de biofertilizante (B). 

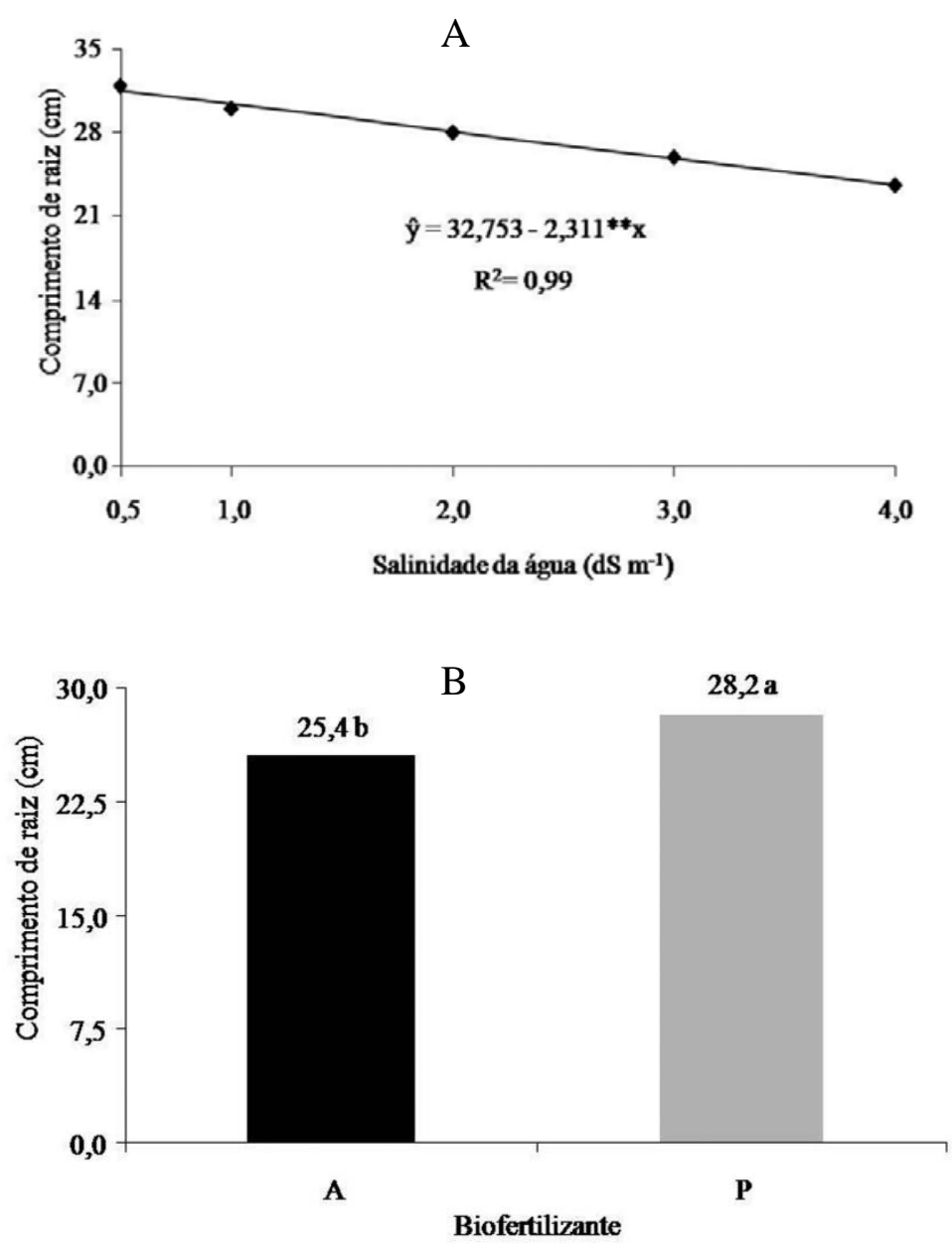

FIGURA 3 - Comprimento de raiz principal de plantas de goiabeira Paluma, aos 70 dias após a emergência, em função de níveis de salinidade da água de irrigação (A), na ausência (ם) e presença ( $\square$ de biofertilizante (B).

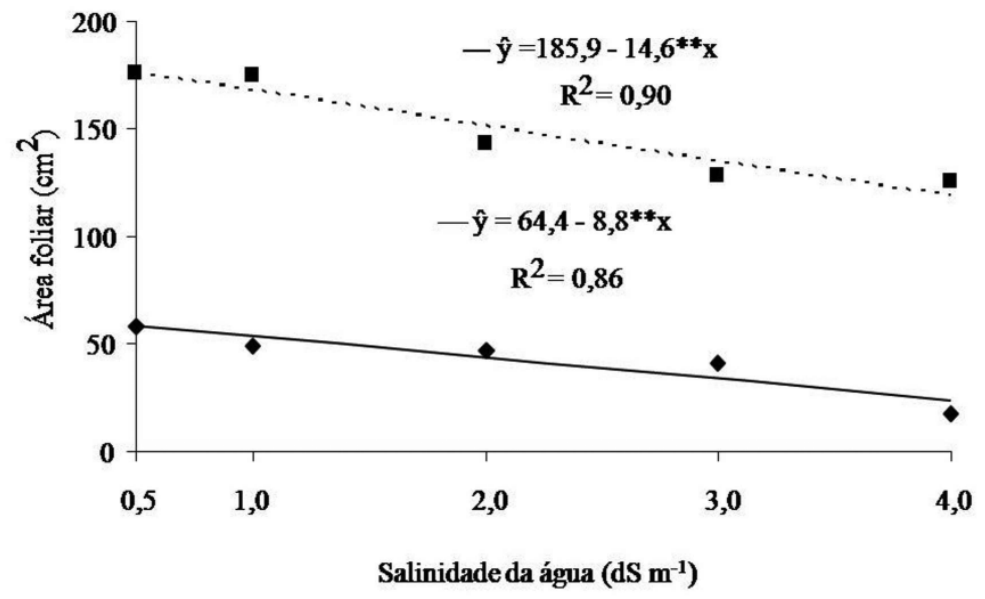

FIGURA 4 - Área foliar de plantas de goiabeira Paluma, aos 70 dias após a emergência, em função de níveis de salinidade da água de irrigação, na ausência (-) e presença (---) de biofertilizante. 

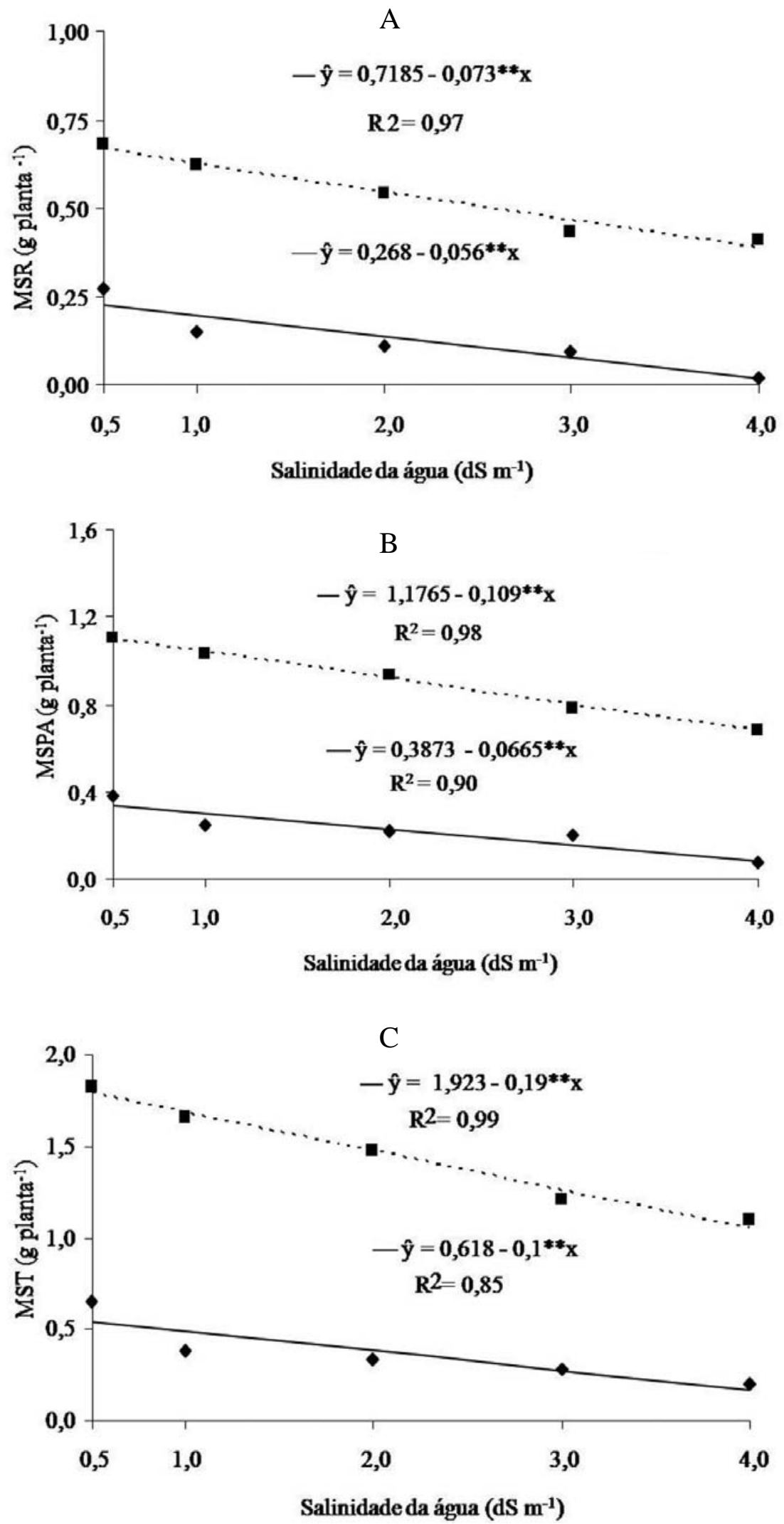

FIGURA 5 - Massa seca de raízes (A), da parte aérea (B) e total (C) de plantas de goiabeira, cultivar Paluma, aos 70 dias após a emergência, em função da salinidade da água de irrigação, na ausência (-) e presença (---) de biofertilizante. 


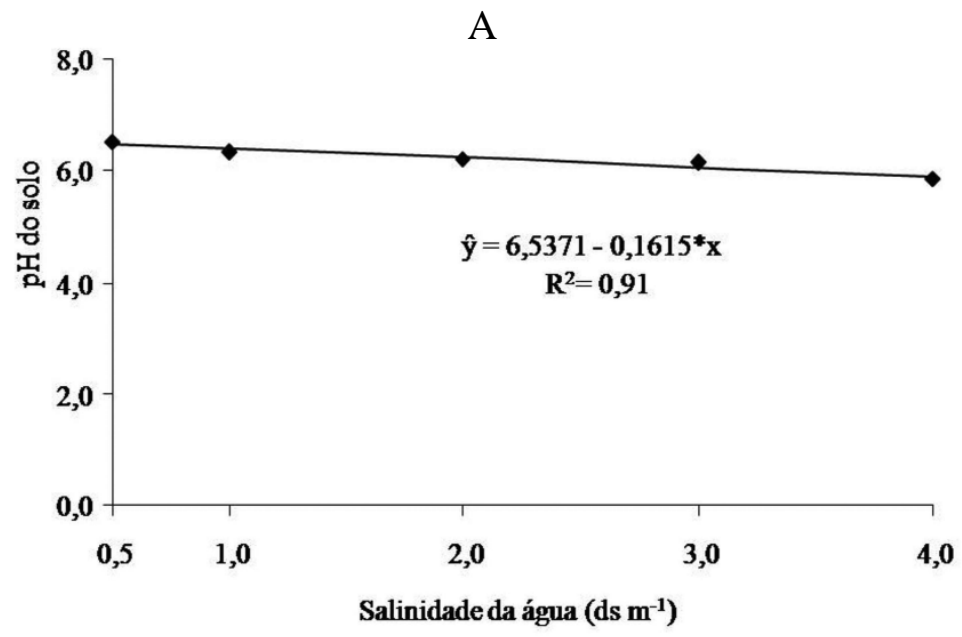

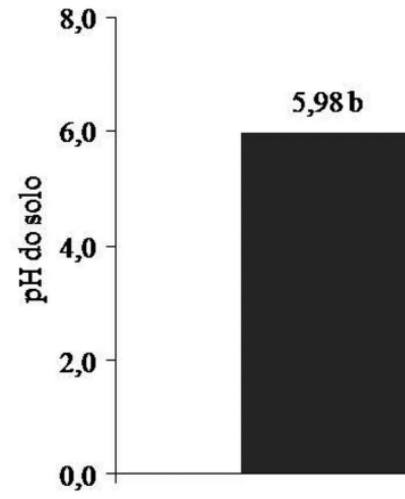

A
B

$$
6,32 \mathrm{a}
$$

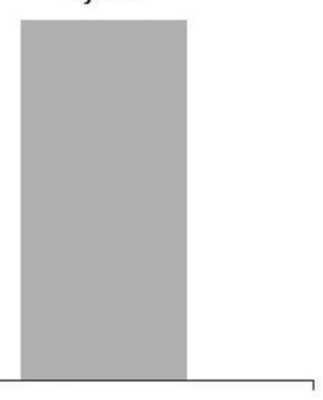

\section{Biofertilizante}

FIGURA 6 - Valores de pH do substrato utilizado para formação de mudas de goiabeira, cultivar Paluma, aos 70 dias após a germinação, em função de níveis de salinidade da água de irrigação (A), na ausência ( $\square$ ) e de biofertilizante na presença ( $\square$ ) (B).

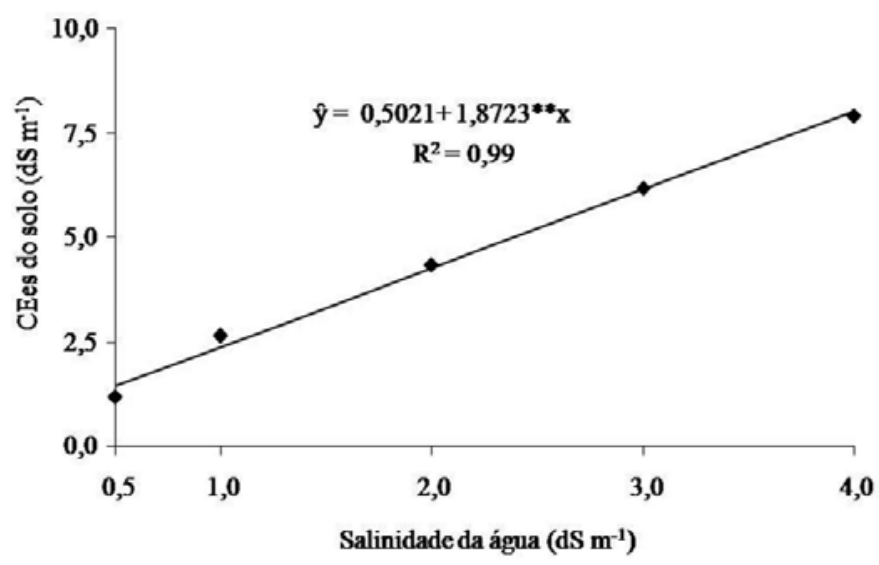

FIGURA 7 - Condutividade elétrica do extrato de saturação de solo, aos 70 dias após a emergência da goiabeira Paluma, em função da salinidade da água de irrigação. 


\section{CONCLUSÕES}

1-O aumento do teor salino das águas elevou o caráter salino do solo e prejudicou o crescimento em altura, diâmetro do caule, área foliar e produção de biomassa da goiabeira, mas com menos intensidade no solo com esterco líquido bovino.

2-O aumento da salinidade da água de irrigação aumenta a salinidade do solo, independentemente da adição ou não do esterco líquido bovino.

3-O esterco líquido bovino atenuou os efeitos degenerativos da salinidade às plantas de goiabeira.

\section{REFERÊNCIAS}

AYERS, R. S.; WESTCOT, D. W. Qualidade da água na agricultura. Campina Grande: Universidade Federal da Paraíba, 1999. 153 p.

CARNEIRO, P.T.; FERNANDES, P.D.; GHEYI, H.R.; SOARES, F.A.L. Germinação e crescimento inicial de genótipos de cajueiro-anão-precoce em condições de salinidade. Revista Brasileira de Engenharia Agrícola e Ambiental, Campina Grande, v.6, n.2, p.199-206, 2002.

CAVALCANTE, I. H. L.; CAVALCANTE, L. F.; OLIVEIRA, F. A.; ARAÚJO, F. A. R. Produção, exportação de nutrientes e composição mineral em dois genótipos de goiabeira, Científica, Jaboticabal, v.33, n. 2, p. 112-119, 2005a.

CAVALCANTE, I. H. L.; SILVA, G. F.; CAVALCANTE, L. F.; SANTOS, D.; BECKMANCAVALCANTE, M. Z. Composição mineral de folhas da goiabeira Paluma em função da adubação sulfato-nitrogenada. Revista Brasileira de Ciências Agrárias, Recife, v. 3, n.1, p. 6-12, 2008.

CAVALCANTE, L. F.; CAVALCANTE, I. H. L.; HU, Y.; BECKMANN-CAVALCANTE, M. Z. Water salinity and initial development of four guava (Psidium guajava L.) cultivar in north-eastern Brazil. Journal of Fruit and Ornamental Plant Research, Skierniewice, v. 15, p. 71-80, 2007.

CAVALCANTE, L. F.; CAVALCANTE, I. H. L.; PEREIRA, K S. N.; DE OLIVEIRA, F. A.; GONDIM, S C.; DE ARAÚJO, F A. R. (2005) Germination and initial growth of guava plants irrigated with saline water. Revista Brasileira de Engenharia Agrícola e Ambiental, Campina Grande, v. 9, n. 4, p. 515-519, 2005b.
FERREIRA, R. G.; TAVORA, F. J. A. F.; HERNANDES, F. F. F. Distribuição da matéria seca e composição das raízes, caule e folhas de goiabeira submetida a estresse salino. Pesquisa Agropecuária Brasileira, Brasília, v. 36, n.1, p. 79-88, 2001.

FREITAS, B. M.; ALVES, J. E. Efeito do número de visitas florais da abelha melífera (Apis mellifera L.) na polinização da goiabeira (Psidium guajava L.) cv. Paluma, Revista Ciência Agronômica, Fortaleza, v. 39, n. 01, p. 148-154, 2008.

GONZAGA NETO, L.; CRISTO, A. S.; CHOUDHURY, M. M. Conservação pós-colheita de frutos de goiabeira, variedade Paluma. Pesquisa Agropecuária Brasileira, Brasília, v. 34, n.1, p.1-6. 1999.

GURGEL, M. T.; GHEYI, H. R.; FERNANDES, P. D.; SANTOS, F. J. S.; NOBRE, R. G. Crescimento inicial de porta-enxertos de goiabeira irrigados com águas salinas. Revista Caatinga, Mossoró, v.20, n. 2, p. 24-31, 2007.

GURGEL. M. T.; FERNANDES, P. D.; GHEYI, H. R.; SANTOS, F. J. S.; BEZERRA, I. L.; NOBRE, R. G. Estresse salino na germinação e formação de porta-enxerto de aceroleira. Revista Brasileira de Engenharia Agrícola e Ambiental, Campina Grande, v.7, n.1, p.31-36, 2003.

HOODA, P. S.; YAMDAGNI, R. Salt tolerance guava (Psidium guajava L. and aonla (Emblica officinalis ) at germination stage. Research and Development Report, Haryana, v. 8, n.1, p. 36-38, 1991.

LIMA, M. A. C.; BASSOI, L. H.; SILVA, D. J.; SANTOS, P. S.; PAES, P. C.; RIBEIRO, P. R. A.; DANTAS, B. F. Effects of levels of nitrogen and potassium on yield and fruit maturation of irrigated guava trees in the São Francisco valley. Revista Brasileira de Fruticultura, Jaboticabal, v. 30, n. 1, p. 246-250, 2008.

MUNNS, R. Comparative physiology of salt and water stress. Plant Cell Environmental, Oxford, v. 25, p. 239-250, 2002.

MUNNS, R.; JAMES, R.A.; L“AUCHLI, A. Approaches to increasing the salt tolerance of wheat and other cereals. Journal of Experimental Botany, Oxford v. 57, p. 1025-1043, 2006. 
PEREIRA, K. S. N.; CAVALCANTE, L. F.; CAVALCANTE, I. H. L.; SILVA, G. F.; GONDIM, S. C. Goiabeira e a salinidade. In: CAVALCANTE, L. F.; LIMA, E. M. Algumas frutíferas tropicais e a salinidade. Jaboticabal: FUNEP, 2006. p. 37-54.

RICHARDS, L. A. Diagnostico y rehabilitacion de suelos salinos y sodicos. México: Departamento de Agricultura de los Estados Unidos de América, 1954. 172p. (Manual de Agricultura, 60)

SANTOS, H.G.; JACOMINE, P.K.T.; ANJOS, L.H.C.; OLIVEIRA, V.A.; OLIVEIRA, J.B.; COELHO, M.R.; LUMBREBAS, J.F.; CUNHA, T.J.F. (Ed.). Sistema brasileiro de classificação de solos. 2.ed. Rio de Janeiro: Embrapa Solos, 2006. 306p.

SILVA, A. B. F.; FERNANDES, P. D.; GHEYI. BLANCO, F. F. Growth and yield of guava irrigated with saline water and addition of farmyard manure. Revista Brasileira de Ciências Agrárias, Recife, v. 3, n. 4, p. 354-359, 2008a.

SILVA, A. F.; PINTO, J. M.; FRANÇA, C. R. R. S.; FERNANDES, S. C.; GOMES, T. C. A.; SILVA, M. S. L.; MATOS, A. N. B. Preparo e uso de biofertilizante líquido. Petrolina: EMBRAPA Semiárido, 2007. 4p. (Comunicado Técnico, 30)
SILVA, E. C.; NOGUEIRA, R. J. M. C.; ARAÚJO, F. P.; MELO N. F.; AZEVEDO NETO. Phisiological responses to salt stress in Young umbu plants. Enviromental and Experimental botany, Oxford, v. 63, p. 147-157, 2008b.

SOUSA, G. B.; CAVALCANTE, L. F.; CAVALCANTE, I. H. L.; BECKMANN-CAVALCANTE, M. Z. Salinidade do substrato contendo biofertilizante para formação de mudas de maracujazeiro irrigado com água salina. Revista Caatinga, Mossoró, v. 21, n. 2, p. 172-180, 2008.

SULTANA, N.; KEDA, T.; KASHEM, M. A. Effect of seawater on photosynthesis and dry matter accumulation in developing rice grains. Photosynthetica, Prague, v. 40, n. 1, p. 115-119, 2002.

TAIZ, L.; ZEIGER, E. Fisiologia vegetal. Porto Alegre: Artmed. 2006. 719p.

TÁVORA, F. J. A. F.; PEREIRA, R. G.; HERNADEZ, F. F. F. Crescimento e relações hídricas em plantas de goiabeira submetidas a estresse salino com Na Cl. Revista Brasileira de Fruticultura, Jaboticabal, v. 23, n. 2, p. 441-446, 2001. 